\title{
La régénération naturelle assistée : perceptions paysannes et effets agro-écologiques sur le rendement du mil (Pennisetum glaucum (L.) R. Br.) dans le bassin arachidier au Sénégal
}

\author{
Baba Ansoumana CAMARA ${ }^{2 *}$, Marième DRAME², Diaminatou SANOGO¹, Daouda NGOM², Marcel \\ BADJI3, Mouhamadou DIOP1 \\ ${ }^{1}$ Centre National de Recherches Forestières, Dakar, Sénégal, BP 2312 \\ 2Laboratoire d'Agroforesterie et d'Écologie (LAFE) - Département d'Agroforesterie - UFR ST - Université Assane SECK \\ de Ziguinchor, Sénégal, BP 523, \\ ¿Laboratoire d'Écologie Végétale - Département de Biologie Végétale, FST, Université Cheikh Anta DIOP, Dakar, \\ Sénégal, BP 5005. \\ *Auteur correspondant : CAMARA Baba Ansoumana : E-mail : ansou1988@yahoo.fr
}

Original submitted in on $18^{\text {th }}$ January 2017. Published online at www.m.elewa.org on $30^{\text {th }}$ April 2017 https://dx.doi.org/10.4314/jab.v112i1.7

\section{RÉSUMÉ}

Objectif : Cette étude a pour objectif d'appréhender l'effet agro-écologique de la Régénération Naturelle Assistée (RNA) sur le rendement du mil dans le bassin arachidier au Sénégal. Elle a été menée dans trois villages de la commune de Tattaguine pendant deux années consécutives.

Méthodologie et résultats : La méthodologie a consisté à évaluer les paramètres de rendement du mil dans un dispositif expérimental en factoriel bloc avec deux facteurs : nombre de tiges par souche et variété de mil. Parallèlement, des enquêtes de perception ont été menées auprès des producteurs sur les différentes combinaisons testées. Les résultats montrent que la RNA avec 4 Tiges/souche a obtenu pendant les deux années un nombre d'épis fertiles significativement plus élevé comparé au témoin. La différence de rendement en grains entre les parcelles témoins et les parcelles de RNA (2 Tiges/souche et 4 Tiges/souche) a commencé à partir de la seconde année avec une augmentation d'au moins $41 \%$ des rendements au niveau des parcelles de RNA comparées aux témoins. Les enquêtes de perceptions montrent que l'ensemble des producteurs s'accordent que le mil se comporte mieux à proximité des arbustes en régénération.

Conclusion et application des résultats : Cette étude fournit des arguments techniques aux acteurs locaux pour une large diffusion de la RNA qui d'une part présente des effets agro-écologiques positifs et d'autre part, si elle est adoptée contribuera à la reconstitution des parcs agroforestiers du bassin arachidier.

Mots-clés : Régénération Naturelle Assistée (RNA) ; Perception paysanne ; Agroforesterie ; Sénégal 
Local people's perceptions on Farmer Managed Natural Regeneration and agro-ecological effects of the practice on millet's yield (Pennisetum glaucum (L.) R. Br.) in the groundnut basin of Senegal

\begin{abstract}
Objective : This study aims to understand the agro-ecological effect of Farmer Managed Natural Regeneration (FMNR) on the yield of millet in the groundnut basin in Senegal. The study was conducted in three villages in the municipality of Tattaguine for two consecutive years.

Methodology and Results: The methodology was to assess the performance parameters of millet in an experimental factorial block with two factors: number of stems per strain and variety of millet. Meanwhile, perception surveys were conducted with producers on the various combinations tested. The results show that the FMNR with 4 stems/strain obtained in the two years a significantly higher number of fertile ears compared to the control. The grain yield difference between control plots and plots RNA (2 stems/strain and 4 stems/strain) started from the second year. This translates to a minimum by a $41 \%$ increase in yields at the RNA plots compared to controls. Surveys show that perceptions of all producers agree that millet performs better near regenerating shrubs. The majority of them prefer to keep 1 or 2 stems/strain.

Conclusion and application of results: This study provides technical arguments to local actors for a large-scale spread of RNA that has a positive share agro-ecological and secondly, if adopted will contribute to the reconstruction parkland groundnut basin.
\end{abstract}

Keywords: Farmer Managed Natural Regeneration (FMNR); peasant perception; Agroforestry; Senegal

\section{INTRODUCTION}

Au Sénégal, les systèmes agraires traditionnels du bassin arachidier qui intégraient les arbres, les animaux et les cultures annuelles permettant une production soutenue ont été abandonnés dans la plupart des cas au profit de la culture continue suivant une rotation annuelle arachide/céréales sèches (Sanogo, 2004). Ce changement de pratiques agricoles a engendré le déboisement puis le dessouchage pour faciliter la mécanisation, d'où la baisse des productions agricoles (Diack, 1998; Diédhiou et al., 1999) et la dégradation du couvert ligneux. Conscient de l'état de dégradation des terres et de la ressource ligneuse, de nouvelles approches relatives à la réhabilitation du couvert végétal émergent de plus en plus en milieu rural. Parmi elles, la Régénération Naturelle Assistée (RNA) occupe une place importante. Elle consiste à laisser au cours du défrichement un / des rejets issus des souches des différents arbres et arbustes pour qu'ils poursuivent leur croissance (Vahsen, 2013). Dans le bassin arachidier du Sénégal, beaucoup d'ONGs, de projets et programmes de

\section{MATÉRIEL ET METHODES}

Zone d'étude : Cette étude a été réalisée dans le CentreOuest du bassin arachidier plus précisément dans la développement préconisaient l'abandon de l'élimination systématique des arbres dans l'espace cultural. Dans certaines localités, les paysans ont adopté cette pratique. C'est le cas des paysans de Kaffrine (Bakhoum, 2012) et de Khatre Sy dans la région de Thiès (Badji et al., 2015). Cependant, d'autres paysans continuent à couper tous les rejets présents dans leurs champs avant la période des cultures. De nombreuses études ont montré que la RNA présente de nombreux avantages socioéconomiques et agro-écologiques (Kalinganire et al., 2007 ; Botoni et al., 2010 ; Larwanou et al., 2012). Cependant, très peu d'entre elles à l'image de celle de Peltier et al. (2014) se sont penchées sur le mode de gestion de la RNA selon les espèces présentes afin d'identifier les meilleures techniques de défrichement qui optimisent le rendement des cultures associées. C'est dans ce contexte que cette étude a été menée. Elle vise à évaluer l'impact de la conservation des rejets de souche sur le rendement du mil.

commune de Tattaguine, département et région de Fatick (figure 1). Les essais ont été installés dans les champs 
paysans pendant deux années consécutives (2012-2013) Ndofonghor.

à Tattaguine Sérère, Keur Mangary et Ngohé

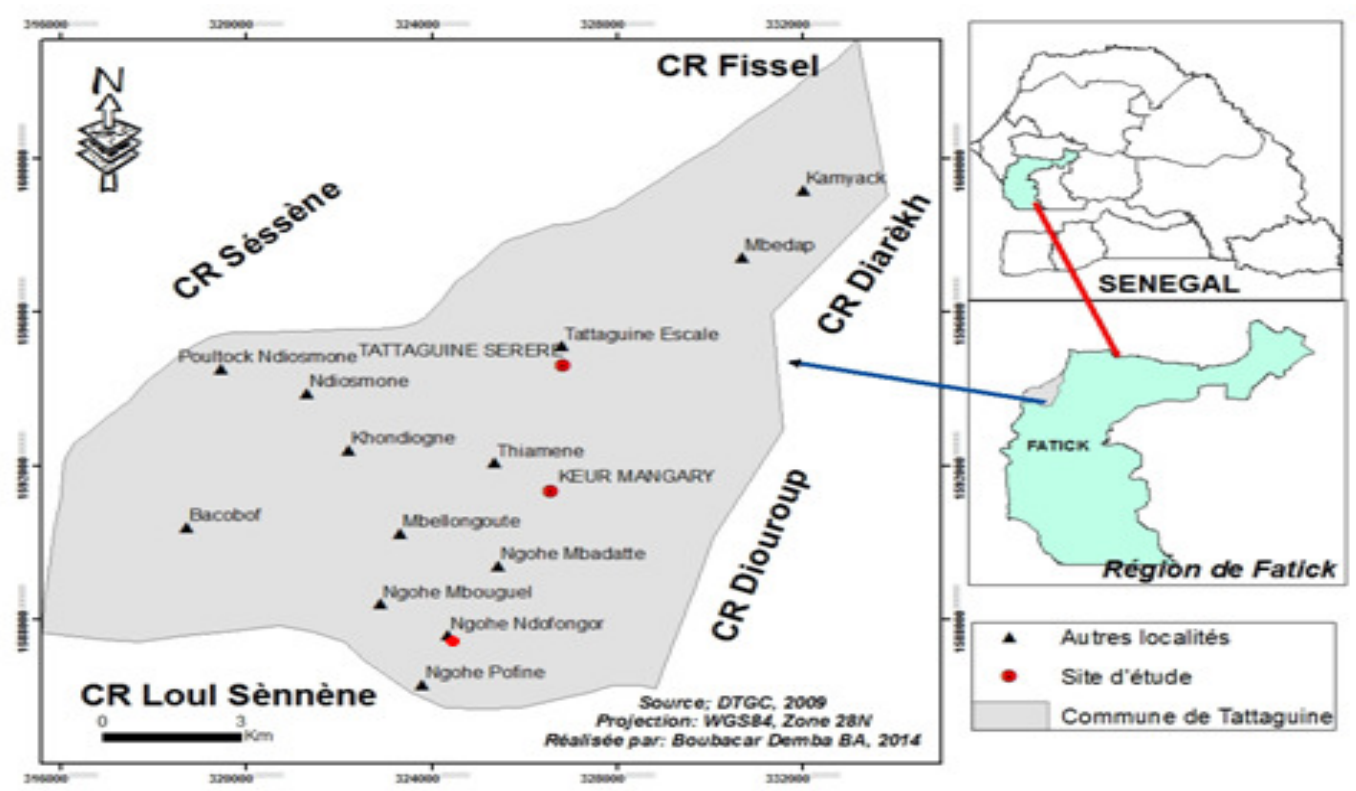

Figure 1 : Carte de la commune de Tattaguine

Le climat est de type tropical sahelo-soudanien marqué par des isohyètes variant entre 400 et $600 \mathrm{~mm}$. La pluviométrie de la commune de Tattaguine varie, autant dans sa distribution temporelle que spatiale, avec une moyenne de 585,6 $\pm 85,9$ mm/an (figure 2 ) sur 11 ans. La quantité de pluie enregistrée pendant les deux années de l'essai a été respectivement de 687,2 mm en 48 jours et
$610 \mathrm{~mm}$ en 41 jours (ANACIMS, 2013). Les sols sont en majorité ferrugineux tropicaux lessivés de nature meuble et perméable, aptes aux cultures céréalières. La végétation est fortement influencée par les actions anthropiques et les conditions climatiques dont la pluviométrie.

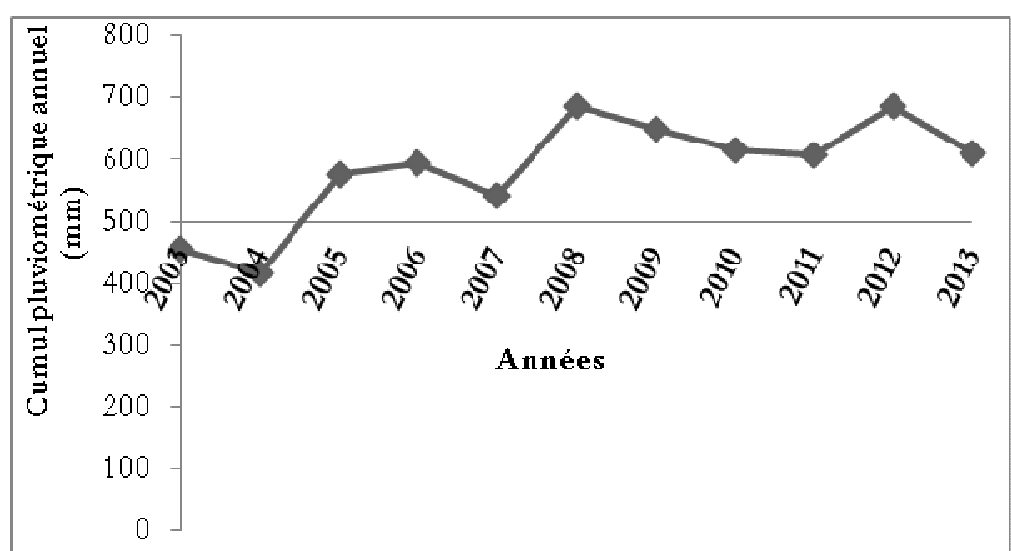

Figure 2 : Variabilité pluviométrique inter-annuelle de la période 2003-2013 dans la commune de Tattaguine (ANACIM, 2013)

Le matériel végétal : La réalisation de cette étude a nécessité l'utilisation de deux variétés de mil (Souna 3 et Locale). Le premier est une variété améliorée à cycle raccourci et le second est une variété non améliorée habituellement utilisée par les producteurs. Ces variétés de mil sont associées aux rejets de souche de Guiera 
senegalensis. Ces derniers ont fait l'objet d'un défrichement amélioré qui a consisté à conserver dans les parcelles, lors de la préparation des champs, 2 ou 4 tiges/souche (photo 1). Le relevé dendrométrique effectué en seconde année d'expérimentation au niveau des tiges conservées montre qu'elles ont un diamètre à $30 \mathrm{~cm}$ et une hauteur de respectivement $8,89 \pm 1,49 \mathrm{~cm}$ et $1,79 \pm$ $0,85 \mathrm{~m}$ avec un diamètre moyen du houppier de 2,14 \pm $1,08 \mathrm{~m}$. Le diamètre a été mesuré à l'aide d'un pied à coulisse tandis que la hauteur de la tige et le diamètre du houppier ont été déterminés à l'aide d'un double décamètre.

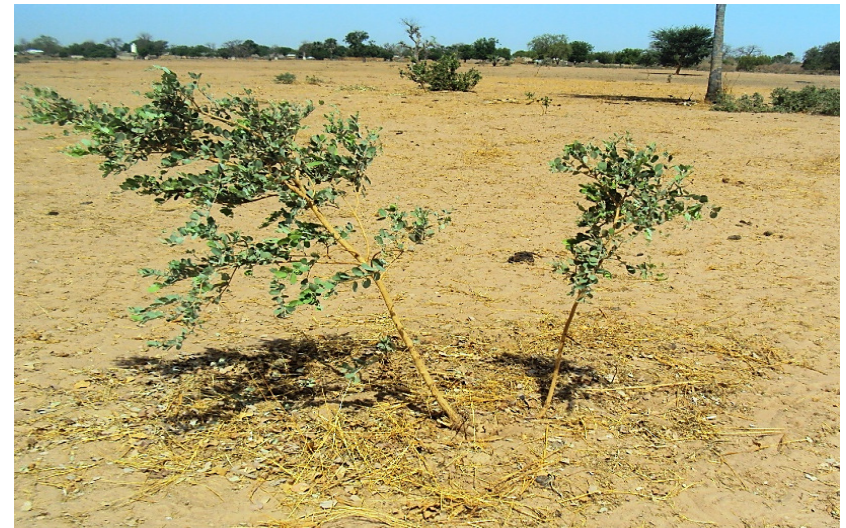

Photo 1 : défrichement amélioré 2 Tiges/souche

Dispositif expérimental : Le dispositif expérimental utilisé pendant les deux années de l'expérimentation est en factoriel bloc répétés 3 fois dans les 3 villages avec des parcelles de $625 \mathrm{~m}^{2}$ séparées entre elles d'une distance minimale de $2 \mathrm{~m}$. La disposition des parcelles d'un bloc est fonction de la présence ou non de souches et du nombre de tige disponible auquel on associe de manière aléatoire une variété de mil (figure 3). Un bloc peut être constitué par les parcelles d'un ou de plusieurs producteurs. Le choix des producteurs était basé sur la disponibilité du matériel ligneux dans leurs parcelles et leur implication dans la gestion des essais. Sur chaque parcelle est associé un traitement combinant deux facteurs : nombre de tiges conservées par souche après défrichement avec trois niveaux (Témoin sans souche, 2 tiges/souche et 4 tiges/souche) et variété de mil avec 2 modalités (Locale et Souna 3). Les semis ont été faits en ayant recours à la traction animale. L'espacement entre les poquets a été d'environ $80 \mathrm{~cm} \times 50 \mathrm{~cm}$. Au moment du démariage, de l'engrais minéral (NPK "15-15-15") a été appliqué à la dose de $150 \mathrm{~kg}-\mathrm{ha}^{-1}$.

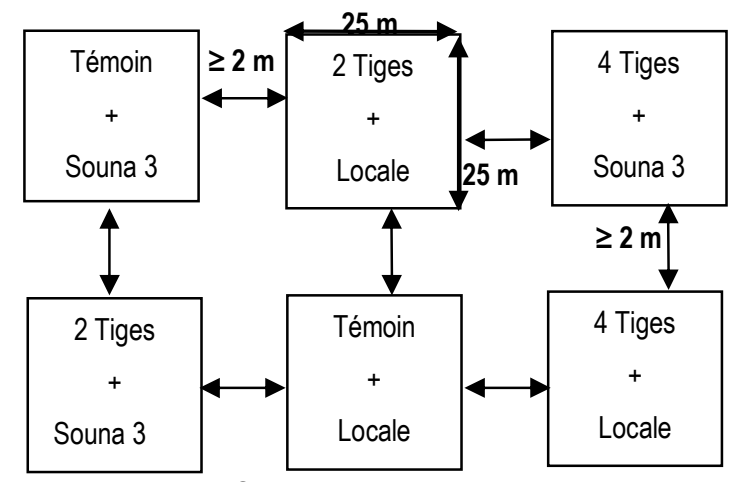

Figure 3 : Schéma d'un bloc expérimental

Technique de récolte et variables mesurées : Elle a consisté à placer deux carrés de rendement de $1 \mathrm{~m}^{2}$ à l'intervalle $[0 ; 2 \mathrm{~m}]$ de la souche avec 2 tiges et 4 tiges. Les deux carrés de rendement ont été installés selon les orientations géographiques Est-Ouest et Nord-Sud. Ces carrés ont été les lieux où les différentes mesures sur les paramètres de rendement du mil ont été effectuées. Pour 
les parcelles témoins (sans souche), la récolte à porté aléatoirement sur quatre carrés de rendement.

Prélèvement des échantillons de sol : Au début de l'étude (année 1), des échantillons (18 échantillons) de sols ont été prélevés un mois après le semis sur $1 / 3$ de la totalité des parcelles de chaque défrichement. Ces échantillons ont été prélevés à deux profondeurs (0-15 $\mathrm{cm}$ et $15-30 \mathrm{~cm}$ ) pour évaluer la teneur du sol en carbone.

Les enquêtes de perception : Des enquêtes qualitatives ( 1 focus group par village) et systématiques (entretien semi structuré) ont été effectuées respectivement dans les trois villages et auprès de 12 producteurs propriétaires

\section{RESULTATS}

Perception des producteurs sur la RNA: Les producteurs ont constaté à l'unanimité $(100 \%)$ que la RNA a des effets agro-écologiques et socio-économiques positifs (tableau 1). Cela s'explique selon eux par le fait que le sol à proximité des souches contient beaucoup plus de litière comparé aux parcelles nues à cause de la chute et de la décomposition des feuilles. L'adoption de la RNA a permis selon les producteurs, la fixation des des parcelles d'essais afin de recueillir leurs perceptions sur la gestion de la RNA, les contraintes liées à sa pratique, les effets agro-écologiques et socioéconomiques.

Analyses statistiques: Les données issues des paramètres de rendement ainsi que celles issues de l'analyse des échantillons de sol ont fait l'objet d'une analyse de variance (ANOVA) et le test de Fisher a été utilisé pour comparer les moyennes avec un intervalle de confiance fixé à $95 \%$. Toutes les analyses ont été faites à l'aide du logiciel XLSTAT. Les données issues des enquêtes de perception ont fait l'objet d'une analyse descriptive dans l'environnement Excel.

dépôts éoliens et la réduction de la dose d'engrais utilisée dans les parcelles sans pour autant compromettre les rendements. Certes, $58 \%$ des producteurs ont identifié certaines contraintes qu'ils rencontrent dans les parcelles de RNA. Cependant, le reste des producteurs (42\%) affirment que grâce au défrichement amélioré et à l'espacement des tiges conservées, il est possible de réduire ces contraintes.

Tableau 1 : Perceptions des producteurs sur la RNA

\begin{tabular}{|c|c|c|}
\hline $\begin{array}{l}\text { Aspect de la RNA } \\
\text { étudié : }\end{array}$ & $\begin{array}{l}\text { Perceptions des } \\
\text { producteurs }\end{array}$ & Justifications \\
\hline Effet agro-écologique & $\begin{array}{l}\text { La RNA a des effets agro- } \\
\text { écologiques positifs ( } 100 \% \\
\text { des producteurs) }\end{array}$ & $\begin{array}{l}\text { croissance des cultures plus rapide à proximité des } \\
\text { souches; } \\
\text { grains; épis plus longs et plus gros de même que les } \\
\text { graturité plus précoce des cultures à proximité des } \\
\text { rejets de RNA ; } \\
\end{array}$ \\
\hline Effet socio-économique & $\begin{array}{l}\text { La RNA a des effets socio- } \\
\text { économiques positifs ( } 100 \% \\
\text { des producteurs) }\end{array}$ & $\begin{array}{ll} & \text { réduction de la dose d'engrais utilisée ; } \\
& \text { source d'aliment pour le bétail ; } \\
& \text { source de pharmacopée ; } \\
& \text { supplément de bois de feu } ; \\
\text { clôtures ou de greniers. } & \text { utilisation des tiges coupées dans la confection de }\end{array}$ \\
\hline Contraintes & $\begin{array}{l}\text { L'adoption de la RNA } \\
\text { présente certaines } \\
\text { contraintes ( } 58 \% \text { des } \\
\text { producteurs) }\end{array}$ & $\begin{array}{l}\text { difficulté d'utilisation de la culture attelée (difficulté } \\
\text { de contournement des tiges, difficulté de devoir } \\
\text { constamment soulever le semoir pour éviter de briser les } \\
\text { lames); } \\
>\quad \text { ralentissement du travail ; } \\
\text { la présence des tiges attire les oiseaux. } \\
\text { granivores; } \\
>\quad \text { plus d'enherbement à côté des souches. }\end{array}$ \\
\hline
\end{tabular}



effets agro-écologiques sur le rendement du mil dans le bassin arachidier au Sénégal

Perception des producteurs sur le nombre de tiges conservées par souche : Le tableau 2 montre que la majorité des producteurs (53\%) pensent que conserver 1 à 2 tiges par souche permet de mieux les entretenir. Bien que $40 \%$ d'entre eux pensent que plus le nombre de tiges conservées est élevé plus la production de litière sera importante et cela pourra se refléter positivement sur la croissance et le rendement des cultures d'où leur option pour les 4 tiges par souche. Seul $7 \%$ des producteurs pensent qu'il serait mieux de couper toutes les tiges lors de la préparation des parcelles puisque les souches vont régénérer plus tard.

Tableau 2 : Perceptions des producteurs sur le nombre de tige conservée par souche

\begin{tabular}{|c|c|cl|}
\hline Nombre de tiges & $\begin{array}{c}\text { Proportion des } \\
\text { producteurs }\end{array}$ & & \multicolumn{1}{c|}{ justification } \\
\hline 4 tiges/souche & $40 \%$ & $>$ & $\begin{array}{l}\text { effet positif sur les cultures, } \\
\text { effet positif sur la fertilité et l'humidité du sol ; } \\
\text { approvisionnement en piquet pour la confection de clôtures. }\end{array}$ \\
\hline 1 à 2 tiges/souche & $53 \%$ & $>$ & $\begin{array}{l}\text { facilite l'entretien des rejets ; } \\
\text { facilite la culture sous traction animale ; } \\
\text { réduit l'effet d'ombrage. }\end{array}$ \\
\hline 0 tige/souche & $7 \%$ & $>$ & $\begin{array}{l}\text { facilite la progression des semoirs ; } \\
\text { réduit les espaces non semées ; } \\
\text { lutte contre l'érosion éolienne. }\end{array}$ \\
\hline
\end{tabular}

Effet de la RNA sur le nombre d'épis fertiles et infertiles récolté : Les résultats des deux années d'étude montrent que les parcelles de RNA avec 4 tiges/souche ont obtenu un nombre d'épis fertiles significativement plus élevé comparé aux parcelles témoin (figure 4a et 4b).

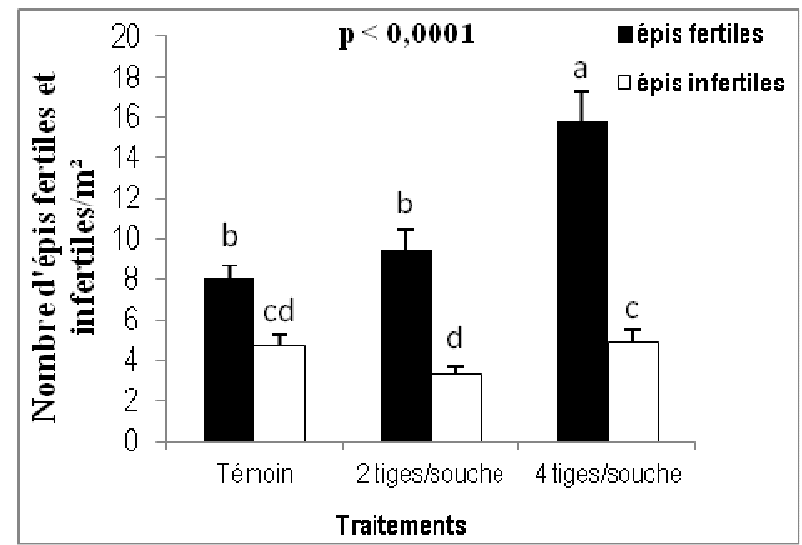

a) Année 1

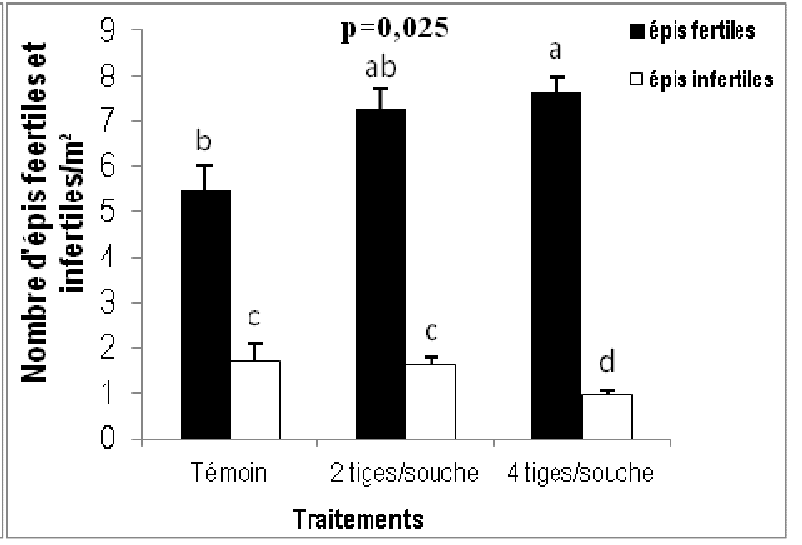

b) Année 2

Figure $4 a$ et $4 b$ : Nombre d'épis fertiles et infertiles en fonction du nombre de tige/souche.

Les barres avec des lettres différentes sont significativement différentes au seuil de $5 \%$ avec des probabilités de Fisher de: $P<0,0001$ (année 1) et $P=0,025$ (année2)

Effet de la RNA sur le rendement en grains : En première année d'essai, seule la RNA avec 4 Tiges/souche combinée à la variété locale a obtenu un rendement en grains significativement plus élevé comparé au défrichement amélioré 2 Tiges/souche et au témoin (figure 5a). Cependant, en seconde année et pour toute variété confondue, les parcelles de RNA (4 Tiges/souches et 2 Tiges/ souche) ont obtenu des rendements supérieurs à ceux des parcelles témoins. Une différence hautement significative est notée lorsque le défrichement amélioré 4 Tiges/souche est combinée à la variété souna 3 (figure $5 \mathrm{~b}$ ). 


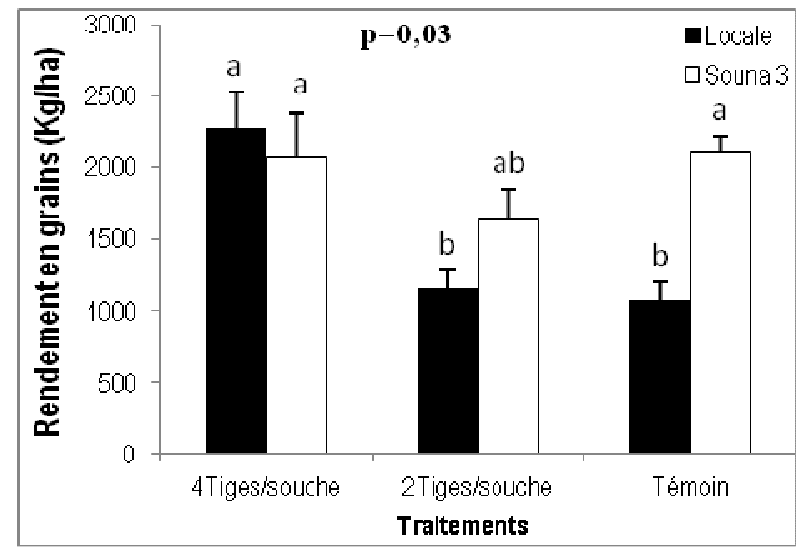

a) Année 1

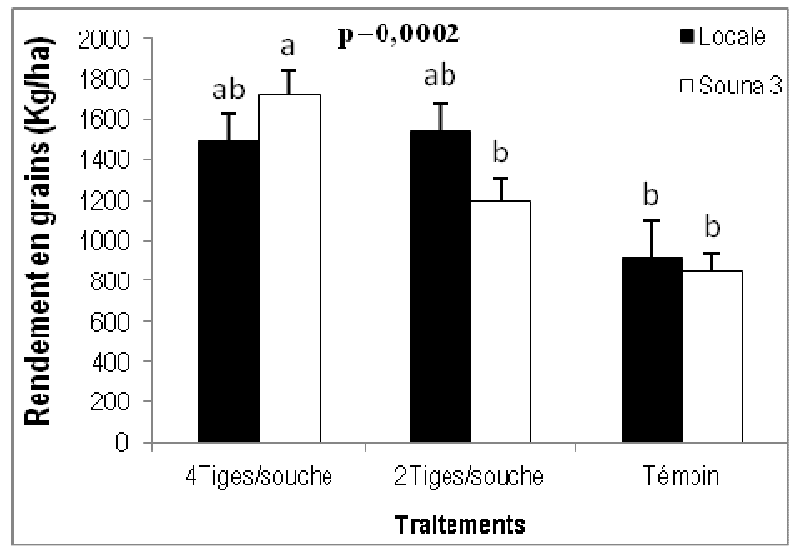

b) Année 2

Figure $5 a$ et $5 b$ : Rendement en grains en fonction du nombre de tige/souche Les barres avec des lettres différentes sont significativement différentes au seuil de $5 \%$ avec des probabilités de Fisher de: $P=0,03$ (année 1) et $P=0,0002$ (année 2)

Effet de la RNA sur la biomasse : Pendant les deux années d'études, les rendements en paille au niveau des parcelles de RNA avec 4 Tiges/souche et 2 Tiges/ souche sont plus élevés que ceux obtenus au niveau des parcelles sans souche (figure 6a et 6b).

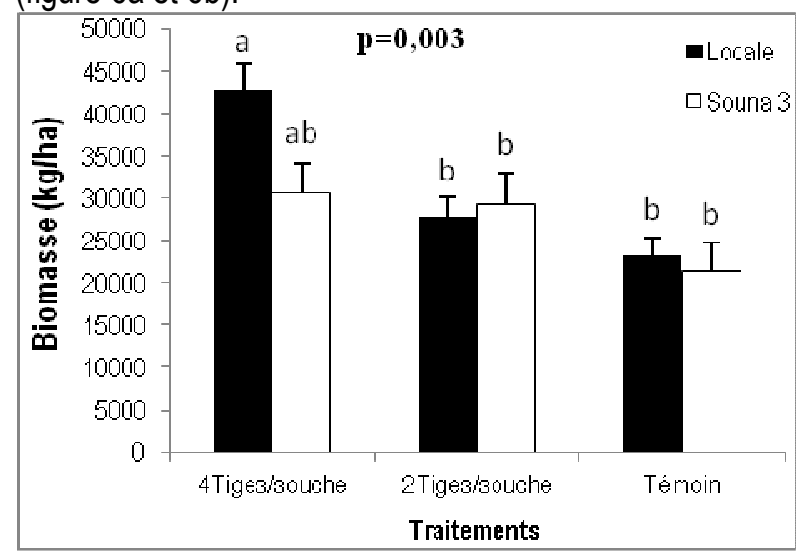

a) Année 1

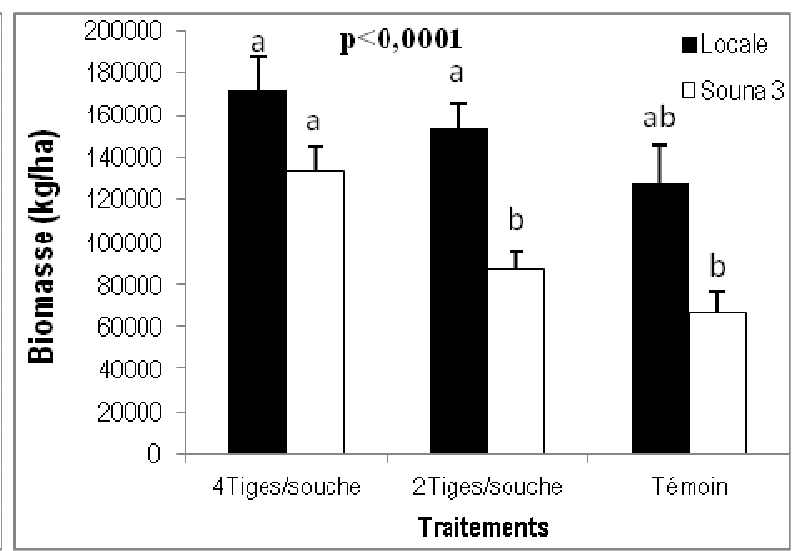

b) Année 2

Figure $6 a$ et $6 b$ : Rendement en paille en fonction du nombre de tige/souche

Les barres avec des lettres différentes sont significativement différentes au seuil de $5 \%$ avec des probabilités de Fisher de: $P=0,003$ (année 1) et $P<0,0001$ (année2)

Caractéristiques de référence du sol: ॥ ressort de l'analyse des échantillons de sol que seul le défrichement amélioré avec 2 tiges/souche a présenté une teneur en carbone significativement plus élevée que celle obtenue au niveau de la parcelle témoin (tableau 3).

Tableau 3 : Effet de la RNA sur la teneur du sol en carbone

\begin{tabular}{|l|c|c|}
\cline { 2 - 3 } \multicolumn{1}{c|}{} & \multicolumn{2}{c|}{ C/total $(\%)$} \\
\cline { 2 - 3 } \multicolumn{1}{c|}{} & $0-15 \mathrm{~cm}$ & $15-30 \mathrm{~cm}$ \\
\hline Témoin & $2,2 \pm 0,33_{\mathrm{b}}$ & $1,7 \pm 0,28_{\mathrm{b}}$ \\
\hline 4 tiges/souche & $3,1 \pm 0,21_{\mathrm{a}}$ & $2,5 \pm 0,17_{\mathrm{a}}$ \\
\hline
\end{tabular}




\section{DISCUSSION}

II ressort des analyses que les parcelles avec 4 tiges/souche présentent le plus grand nombre d'épis fertiles. Cela pourrait s'expliquer par le fait que la présence des arbustes au niveau des parcelles accroitt l'humidité du sol tout autour des souches si bien que les cultures associées supportent mieux le stress hydrique durant leurs différents stades de développement et qu'elles pourront boucler leur cycle de maturité. Des études ont montré que le déficit hydrique en cours de cycle notamment en période de montaison affecte le nombre d'épis et la fertilité des épis (De Rouw, 2000 ; Ali Dib et al., 1992). Or, il a été établi par Dick et al., (2009) que ces arbustes (Guiera senegalensis et Piliostigma reticulatum) ont un effet positif en terme de disponibilité/d'efficience de l'eau pour les cultures et pour la conservation de l'eau, matière précieuse dans cet environnement semi-aride. Louppe (1991) évoque des tendances plus élevées de l'évaporation du sol au niveau des parcelles nues comparées aux parcelles peuplées de Guiera senegalensis. En seconde année et pour toute variété confondue, les parcelles de RNA (4 Tiges/souches et 2 Tiges/ souche) ont obtenu des rendements supérieurs à ceux des parcelles témoins. $\mathrm{Ce}$ résultat est en phase avec la perception des producteurs qui affirment que la RNA a des effets agro-écologiques positifs tant sur la protection et la gestion de la fertilité du sol que sur le comportement des cultures. Cela s'expliquerait par le fait que la biomasse végétale laissée sur et dans le sol au moment de la défriche a un effet sur le rendement du mil. Une étude réalisée par Yelemou et al., (2007) sur la perception paysanne de Piliostigma reticulatum a révélé que $98 \%$ des personnes interrogées notent une croissance végétative meilleure et rapide lorsqu'un paillage de la culture est réalisé avec des feuilles de Piliostigma reticulatum. La présence et la gestion des arbustes dans les champs permet une amélioration notable du rendement de la céréale associée

\section{CONCLUSION}

La conservation et la gestion des rejets ligneux dans les champs à travers la RNA a permis d'étudier leurs effets sur le rendement du mil. A l'issu de cette étude, nous pouvons dire que le rendement en grains de la deuxième année d'expérimentation au niveau de la RNA avec 4 tiges/souche et 2 tiges/souche est plus élevé que celui obtenu au niveau de la parcelle nue. Les meilleures performances pour le nombre d'épis fertiles et le rendement en paille sont obtenues pour l'ensemble des variétés au niveau de la parcelle avec 4 tiges conservées.
(Kizito et al., 2006 ; Abasse et al., 2013 ; Dossa et al., 2013 ; Binam et al., 2015). Les souches entretiennent des interactions positives avec la biomasse microbienne et agissent par conséquent sur la minéralisation du carbone et de l'azote se traduisant par des teneurs moyennes en carbone et azote totaux qui diminuent lorsqu'on s'éloigne des souches (Faye 2000 ; Wezel et al., 2000; Housman et al., 2007 ; Dossa et al., 2009). Guiera senegalensis et Piliostigma reticulatum facilitent l'alimentation hydrique de la culture associée du fait qu'elles réalisent la redistribution hydraulique (Kizito et al., 2007). Dans le cadre de cette étude, les résultats de l'analyse du sol ont montré que seul le défrichement amélioré 2 tiges/souche a présenté une teneur en carbone du sol dans les deux horizons considérées significativement plus élevé que celle des autres traitements. Cela s'expliquerait par le fait que pour aboutir à 2 tiges/souche il arrive de couper parfois plus de tige qu'on en coupe pour aboutir à 4 tiges/souche. La biomasse coupée est utilisée pour le paillage. Par ailleurs, des études récentes sur les parcs agroforestiers sahéliens ont révélé que le sol sous les arbres a une porosité plus grande comparé aux zones nues (Sanou et al., 2010). Pour la conduite des cultures sous traction animale, $53 \%$ des producteurs pensent que conserver 1 à 2 tiges par souche lors du défrichement est moins gênant que conserver 4 tiges. Néanmoins, vu la fragilité des jeunes rejets dans cette zone, il serait plus pertinent de conserver 4 tiges/souche les premiers années puisque le rendement en grains obtenu avec ce défrichement de 2 ans ne semble pas présenter un effet négatif sur la productivité des variétés de mil utilisées. Charreau (1979) trouve que lorsque les combinaisons (arbres et cultures) sont judicieusement choisies, elles enregistrent des augmentations de rendement pouvant aller de 20 à $90 \%$, sans nécessiter d'investissement de la part du paysan.

Cependant, $53 \%$ des producteurs pensent que, pour la conduite des cultures sous traction animale, conserver 1 à 2 tiges par souche lors du défrichement est moins gênant que 4 tiges. Toutefois dans cette zone, vu la fragilité des jeunes rejets de tiges, il serait plus pertinent d'adopter le type de défrichement avec 4 tiges les premiers années puisque le rendement en grains obtenu avec ce défrichement de 2 ans ne semble pas présenter pour le moment un effet négatif sur la productivité des variétés de mil utilisées. 


\section{REMERCIEMENTS}

Les auteurs remercient le projet CerLivesTrees pour le financement des activités de recherches ayant abouti à cette publication.

\section{REFFERENCES BIBLIOGRAPHIQUES}

Abasse T, Yaye A, Zakari AH, Assoumane IA, Toudou A. 2013. Influence des Parcs agro forestiers à Piliostigma reticulatum sur l'infestation des plants de mil par les insectes floricoles et Coniesta ignefusalis (Hmps) (Lépidoptère : Pyralidae) dans la zone d'Aguié au Niger. J. appl. Biosci. 66:5140-5146.

Ali Dib T, Monneveux P, Araus JL. 1992. Adaptation à la sécheresse et notion d'idéotype chez le blé dur II : caractères physiologiques d'adaptation. Rev. Agronomie 12 (1992), 381-393.

Badji M, Sanogo D, Coly L, Diatta, Akpo LE. 2015. La Régénération Naturelle Assistée (RNA) comme un moyen de reverdir le bassin arachidier au Sénégal: cas du terroir de Khatre Sy. Int. J. Biol. Chem. Sci. 9(1): 234-245. DOI http://dx.doi.org/10.4314/ijbcs.v9i1.21

Bakhoum C. 1995. Influence de Sterculia setigera del. «Mbepp» sur les rendements des cultures annuelles (arachide, mil, sorgho) au Sud-Est du bassin arachidier du Sénégal, Mémoire de DEA, ISE, Faculté des Sciences et Techniques, UCAD, Sénégal, $p$

Bakhoum C. 2012. Diversité et capacities de regeneration naturelle du peuplement ligneux dans les systems agraires du Bassin arachidier en zone Soudano-sahalienne (region de Kaffrine, Sénégal). Thèse de doctorat de $3^{\text {ème }}$ cycle, spécialité : écologie, agroforesterie, Université Cheikh Anta DIOP de Dakar, Sénégal, $151 \mathrm{p}$.

Binam JN, Place F, Kalinganire A, Hamade S, Boureima M, Tougiani A, Dakouo J, Bayo M, Sanogo D, Badji M, Diop M, Bationo BA, Haglund E. 2015. Effects of farmer managed natural regeneration on livelihoods in semi-arid West Africa. Society for Environmental Economics and Policy Studies and Springer Japan 2015

Charreau C, 1979. Rôle des arbres dans les systèmes agraires des régions semi-arides tropicales d'Afrique de l'Ouest. In. Le rôle des arbres au Sahel. Compte rendu du colloque à Dakar (Sénégal) du 5 au 10 Novembre 1979. pp. 3336.

Chopart JL, Nicou R. 1976. Influence du labour sur le développement radiculaire de différentes plantes cultivées au Sénégal. Conséquences sur leur alimentation hydrique. L'Agronomie Tropicale 31 (1): 7-28.

De Rouw A. 2000. Rendements élevés et rendements sûrs : deux objectifs des agriculteurs Sahéliens au Niger, pp. 120-126, In Floret Ch. Et Pontanier $R$. (éd.) « La jachère en Afrique Tropicale. Rôles, Aménagement, Alternatives ».

Diack M. 1998. Piliostigma reticulatum dans un parc à Cordyla pinnata : effet sur la régénération des sols dégradé au sahel. Mémoire de titularisation ISRA/CNRA. 48p.

Dick RP, Sène $M$, Diack $M$, Khouma $M$, Badiane A, Samba NAS, Diédhiou I, Lufafa A, Dossa E, Kizito F, Diédhiou S, Noller J, Dragila M. 2009. The Native Shrubs Piliostigma reticulatum and Guiera senegalensis: The Unrecognized Potential to Remediate Degraded Soils and Optimize Productivity of Sahelian Agroecosystems. International Colloquium for the Great Green Wall of Africa. UNDP, World Bank, and Senegal Ministry of the Environment. Dakar, Senegal. Feb. 11-12, 2009. 13p.

Diédhiou I, Diatta M, Diouf M. 1999. Influence de la densité de plantation de deux acacias sur l'alimentation hydrique du sorgho en zone semiaride du Sénégal, pp. 648-655 In Floret Ch. Et Pontanier R. (éd.) " La jachère en Afrique Tropicale. Rôles, Aménagements, Alternatives

Dossa EL, Khouma M, Diédhiou I, Sène M, Kizito F, Badiane AN, Samba SAN, Dick RP. 2009. Carbon, nitrogen and phosphorus mineralization potential of semiarid Sahelian soils amended with native shrub residues. Geoderma 148:251260.

Dossa EL, Diédhiou I, Khouma M, Sène M, Badiane AN, Samba SAN, Assigbetse KB, Sall S, Lufafa A, Kizito F, Dick RP, Saxena J. 2013. Crop productivity and nutrient dynamics in a shrubbased farming system of the Sahel. Agron. J. 105:1237-1246.

Faye EH. 2000. Étude de la dynamique des souches ligneuses dans le cycle culture-jachère en zone soudanienne. Mémoire de fin d'études, Université polytechnique de Bobo Dioulasso, option Eaux et Forêts. 103p. 
Grouzis M, Akpo LE, 1998. Dynamique des interactions arbre-herbe en milieu Sahélien, Influence de l'arbre sur la structure et le fonctionnement de la strate herbacée. In l'acacia au Sénégal. Orstom édition, 1998, ISBN : 2-7099-1423-9. pp 37-46.

Kizito $F$, Dragila M, Sène M., Lufafa A. Dick RP, Diédhiou I, Dossa E, Khouma M, Ndiaye S, Badiane A, 2006. Seasonal soil water variation and root patterns among two semi-arid shrubs coexisting with Pearl millet in Senegal, West Africa. J. Arid Environ. 67, 436-455.

Kizito $F$, Sène M, Dragila MI, Lufafa A, Diédhiou I, Dossa E, Cuenca R, Selker J, Dick RP. 2007. Soil water balance of annual crop-native shrub systems in Senegal's Peanut Basin. Ag. Water Management 90:137 - 148.

Larwanou M, Moustapha AM, Rabe ML, Iro D. 2012. Contribution de la Régénération Naturelle Assistée des ligneux dans l'approvisionnement en bois des ménages dans le département de Magaria (Niger). Int. J. Biol. Chem. Sci. 6(1): 2436. DOI : http://dx.doi.org/10.4314/ijbcs.v6i1.3

Louppe D. 1991. Guiera senegalensis, espèce agroforestière? Bois et Forêts des Tropiques $228 ; 41-57$.

Peltier R, Dubiez E, Diowo S, Gigaud M, Marien JN, Marquant B, Peroches A, Proces P, Vermeulen C. 2014. Assisted Natural Regeneration in slash-and-burn agriculture: Results in the Democratic Republic of the Congo. Bois et Forêts Des Tropiques, 2014 , Nº 321 ( 3 )
Sanogo D, Ayuck E, Dia YK. 2004. Appropriation de technologies agroforestières: cas de la haie vive dans le Sud bassin arachidier du Sénégal. La haie vive dans le Sud du bassin arachidier du Sénégal. Etudes et Recherches Sahéliennes $n^{\circ} 10: 7-17$ Institut du Sahel/INSAH.

Thiobane M. 2013. Lutte contre la désertification: les bons points de la RNA et de l'agroforesterie. In. Régénération Naturelle Assistée pour reverdir les terres de cultures. Rev. Les cahiers du GREP. N 7 mai 2013. pp. $8-9$.

UICN, GREEN Sénégal, FENOP et Réseau MARP Burkina. 2010. Rapport de caractérisation de cas de deux paysans innovateurs dans la région nord du Burkina Faso en matière de la Régénération Naturelle Assistée: cas d'Ali OUEDRAOGO et d'Ousséni KINDO. 35p.

Vahsen M. 2013. L'importance de l'arbre sur la fertilité des sols. In. La terre, j'en fais mon affaire... Bulletin de ADG news, 31[01/02/2013]. Fiche $\mathrm{N}^{\circ}$ 8. pp. 13-14.

Yelemou B, Bationo BA, Yameogo G, MillogoRasolodimby J. 2007. Gestion traditionnelle et usages de Piliostigma reticulatum sur le Plateau central du Burkina Faso. Bois et Forêts desTropiques $291: 55-66$.

Wezel A, Rajot JL, Herbig C. 2000. Influence of shrubs on soil characteristics and their function in Sahelian agro-ecosystems in semi-arid Niger. J. Arid Environ. 44:383-398. 